\title{
Patient Satisfaction and Marketing Effectiveness in Private Hospitals in the Kingdom of Bahrain
}

\author{
Fatima Husain Juma \\ College of Administrative and Financial Sciences, AMA International University \\ P.O.Box: 804, Salmabad, Kingdom Of Bahrain
}

\begin{abstract}
The goal of patient satisfaction is not a simple business metric that will slightly improve sales, several studies found that satisfied patients actually respond better and show greater compliance with their treatment. In addition, the increasing number of private healthcare facilities in the kingdom of Bahrain means that the market is becoming more competitive and patients have more choices if they feel unsatisfied with their healthcare provider. This studies whether patient satisfaction is an aggregate function of marketing effectiveness, personnel quality, the clinical care process and hospital infrastructure. Measuring these different aspects can help establish areas of improvement and increase the overall effectiveness of the healthcare system. 283 patients from different private hospitals have participated in this study by responding to the developed questionnaire. Means, standard deviations, and f-values were used to review the results. In light of the hypothesis formulated, it was found that marketing effectiveness, the clinical care process and hospital infrastructure have statistically significant impact on patient satisfaction and the null hypothesis is rejected.
\end{abstract}

Keywords: Hospital Service, Healthcare, Service Marketing, Patient Satisfaction, Personnel quality, Clinical care process, Hospital Infrastructure

DOI: $10.7176 / \mathrm{JMCR} / 72-05$

Publication date:October $31^{\text {st }} 2020$

\section{Introduction and Background}

The government of the Kingdom of Bahrain has always shown a strong commitment to its honest principles of universal access to high-quality healthcare services. The government has established a nationwide network of clinics and hospitals to try to achieve its goals of providing access to high quality healthcare services to the population of the Kingdom of Bahrain. However, the changing demographics and the distinct lack of resources, are making it very difficult for the government hospitals to cope with the increasing demand for healthcare services (Ministry of Health, 2015). This has given rise to an increasing number of private hospitals and clinics around the island.

\subsection{Introduction}

As patients are willing to pay additional amounts to avoid long queues and receive higher quality service (Gill \& Kaur, 2019), this researcher believes that it is important to know whether patients are satisfied with the care they receive, not only to ensure that patient expectations match their perception, or that expenditures made by the management team shows the intended results as private hospitals face increasing financial challenges and health reform policies (Gelb, 2015), but also because over the last several years, it was observed that Patient satisfaction is a core metric that can be used to predict the effectiveness of treatments and service quality provided in medical clinics.

If fact, numerous research studies have been done over time to understand the different predictors that influence patient satisfaction. Much time and effort has gone into identifying and formulating various theories and models. As such, the importance and value of patient satisfaction cannot be overstated.

Delighted customers are loyal customers and businesses have spent a lot of time and effort to monitor their customer's satisfaction. They go to great length to ensure that their staff are providing their customers with quick, helpful and responsive services. This is no different for sick patients. If a patient's expectations are not met, not only will they shy away from coming back to the doctor who treated them, but it can also affect their recovery. It has been proven that dissatisfied patients show less compliance to their medical care than satisfied ones (Krot \& Rudawska, 2019) (Joseph \& Ganesan, 2015).

In the kingdom of Bahrain, there is increasing evidence that patients are unsatisfied with the services provided by public hospitals. This could be clearly seen from the proliferation of private hospitals around the kingdom, as there are currently 22 private hospitals scattered around the island as compared to only 7 public hospitals (Ministry of Health, 2017). Couple that with the assumed efficiency of these hospitals (Gill \& Kaur, 2019), the increasing number of native and expatriate workers in the private sector (Ministry of Health, 2015) - who are usually issued medical insurance policies for them and their families by their companies - and it becomes clear why more than $22 \%$ of population prefer to endure treatment in private hospitals. This figure does not even take into account the number of people visiting the large number of small private clinics (Ministry of Health, 2017). 
The lack of satisfaction can be traced back to several key factors such as doctor courtesy, doctor attentiveness, confidentiality, time allotment for the patient to describe their illness, proper explanation of illness and treatment including doses and side effects. Other factors include follow-up appointments, asking for consent before performing any action and facility related factors such as whether the reception desk is easy to locate, suitability of waiting area, availability of drinking water, courtesy of staff as well as overall cleanliness of the facility. Addressing these gaps between patient's needs and actual service can improve the level of patient satisfaction throughout the hospital (Gill \& Kaur, 2019).

\subsection{Statement of the Problem}

More than a fifth of the population of the Kingdom of Bahrain prefer the services of the private healthcare system over the services provided free of charge by the Government. With the demand in healthcare only set to rise due to the aging and growth of the population and the increasing commonness of chronic health problems such as diabetes, high blood pressure and high cholesterol, privatization is one of the best ways to increase supply while maintaining the quality of the services provided (Khouri \& De Boysson, 2018).

To sustain a healthy relationship between the patient and the private healthcare provider, the following needs are to be studied and addressed:

- The current level of satisfaction of patients attending private healthcare hospitals in the Kingdom of Bahrain

- The Criteria affecting the level of satisfaction of patients attending private medical centers in the kingdom of Bahrain.

- How to improve any identified gaps in the level of patient satisfaction

\subsection{Research Questions}

In view of the problem statement, this research endeavors to answer the following questions:

1. Does marketing effectiveness have a statistically significant impact on the level of patient satisfaction in private medical centers in the kingdom of Bahrain?

2. Does hospital infrastructure have a statistically significant impact on the level of patient satisfaction in private medical centers in the kingdom of Bahrain?

3. Does the clinical care process have a statistically significant impact on the level of patient satisfaction in private medical centers in the kingdom of Bahrain?

4. Does personnel quality have a statistically significant impact on the level of patient satisfaction in private medical centers in the kingdom of Bahrain?

\subsection{Research Hypothesis}

H01: Marketing Effectiveness has no significant effect on the level of patient satisfaction in private hospitals in kingdom of Bahrain.

H02: Hospital infrastructure has no significant effect on the level of patient satisfaction in private hospitals in kingdom of Bahrain.

H03: The clinical Care Process has no significant effect on the level of patient satisfaction in private hospitals in kingdom of Bahrain.

H04: There is no significant effect of personnel quality on the level of patient satisfaction in private hospitals in kingdom of Bahrain.

\subsection{Theoretical Framework}

Many theories can be found that have been conducted to observe patient satisfaction. (Zarei, Daneshkohan, Pouragha, Marzban, \& Arab, 2015) with their study on Iranian hospitals, concluded that there are several key dimensions related to healthcare service quality, namely, infrastructure, process of clinical care, staff quality, process of administration, safety, overall experience of the medical services and care and social responsibility. Similar dimensions were also used in a study by (Velmurugan, Shubasini, Saravana Bhavan, \& Selvam, 2019), in terms of constructs and the constituent items. In this study, the researchers had created eight aspects, namely infrastructure, safety indicators, process of clinical care, personnel quality, administrative process, Hospital Image, social responsibility, and the hospital trustworthiness from the perspectives of both the attendants and the patients. Hospital image specifically, was found to be one of the key factors that influences patient choices, satisfaction and loyalty (Al-Balushi \& Rahman Khan, 2017).

Based on an extensive literature review on the topics of patient satisfaction and service quality, the important aspects of patient-perceived healthcare service quality standards have been recognized and used as a tool in measuring the viewpoint of healthcare service quality of the patient. Listed below are the dimensions of patientperceived satisfaction and quality service in the private medical healthcare used in this research 


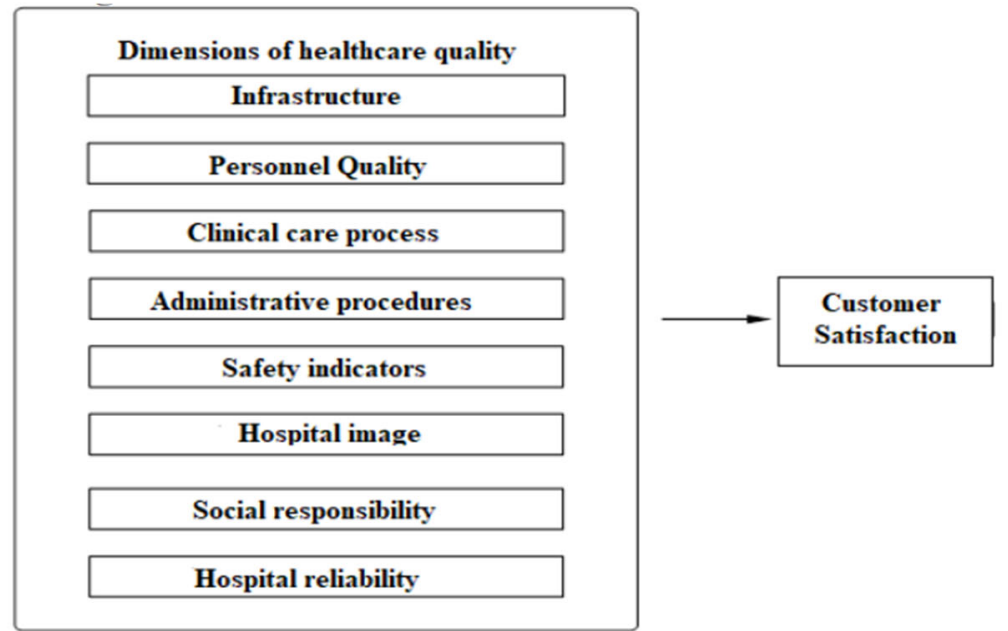

Figure 1.1: Theoretical Framework

Source: (Velmurugan, Shubasini, Saravana Bhavan, \& Selvam, 2019)

\subsection{Conceptual Framework}

The conceptual framework of this research is developed based on the theoretical framework and the statement of problem that needs to be addressed. The study has developed a conceptual framework based on the identified factors of patient satisfaction and marketing effectiveness in the private medical centers in kingdom of Bahrain. The conceptual framework of this study measured the impact and influence of the independent variables identified in this study on the dependent variable. In this research the dependent variable was the overall patient satisfaction while the Independent variables were doctor patient relationship, infrastructure of the private medical center and the effectiveness of the marketing system. This framework encompasses four of the eight factors identified in the theoretical framework, namely infrastructure, Personnel Quality, Clinical Care Process and administrative procedure (Marketing Effectiveness). This will allow the concentration on these meaningful factors while the remaining factors can be addressed in future studies.

The diagram below is a graphical representation of the framework developed by the researcher.
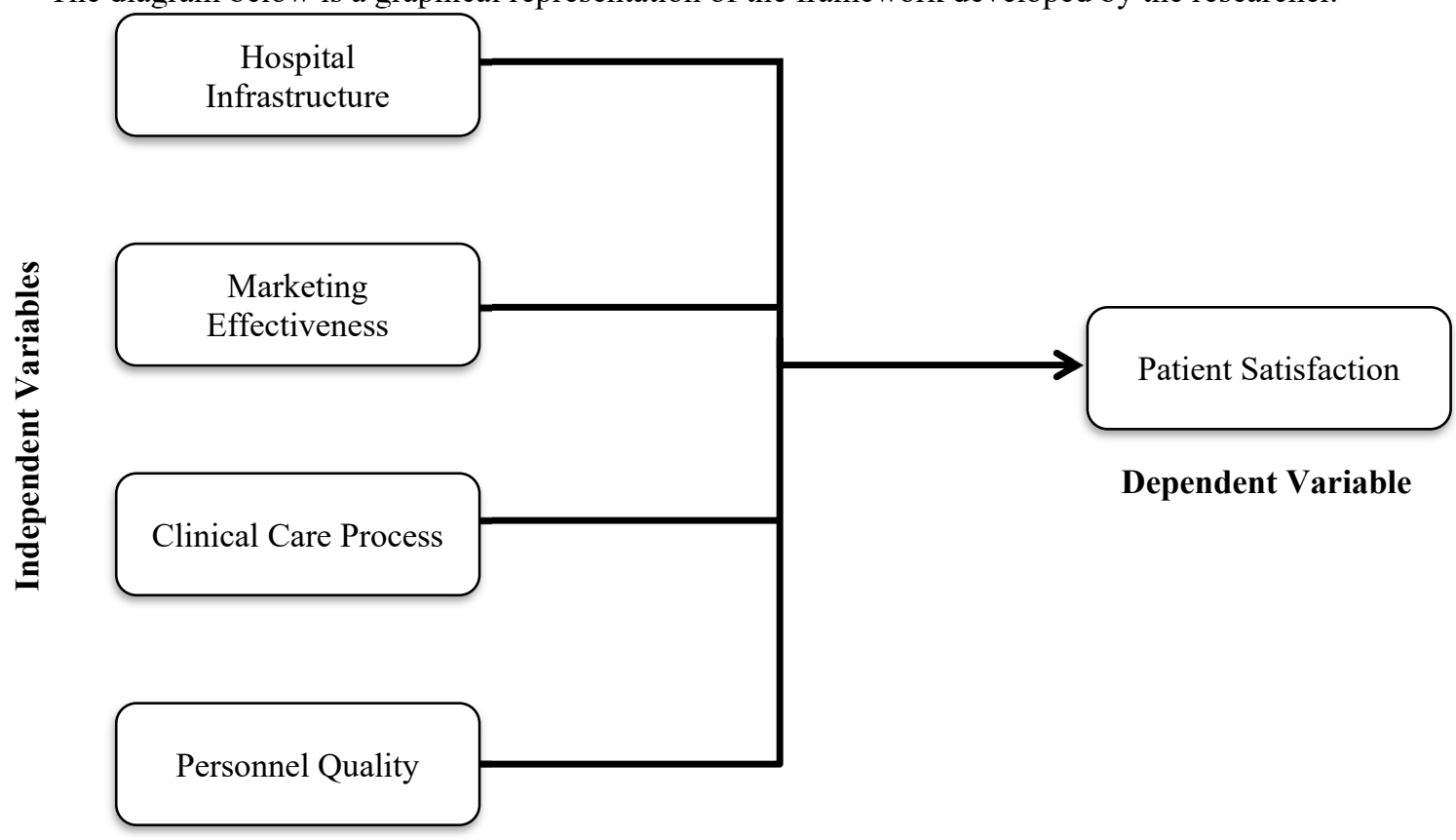

Figure 1.2. Conceptual framework

\section{Review of Related Literature and Studies}

This Chapter will present a detailed review of existing literature related to patient satisfaction in private medical centers. Focusing on knowledge and findings from existing literature relevant the topic. 


\subsection{Related Literature}

Customer satisfaction is a very essential and important part of the modern business theory and best practice across all sectors around the globe. Its core definition depends on the fact that organizations prosper and survive through achieving customer satisfaction and needs. This is by no means a new topic, there are numerous studies conducted on satisfaction dating as far back as the 1960s such as the Carsozo study on "consumer effort, expectations and satisfactions" issued in 1965 (East, Singh, Wright, \& Vanhuele, 2017).

This is in fact the case for the healthcare sector, where patient satisfaction has emerged at the forefront of research concerning the quality of care provided and the existing service delivery structures. Patient satisfaction is known to be the most important objective of health care services and it depends on a variety of factors (Mukhtar, et al., 2013). Patients are no longer a "passive recipient" but are considered an "active participant" in modern medicinal philosophies and a "main stakeholder" for healthcare organizations as medical centers become more "patient Centric" (Gajovic, et al., 2012). This sentiment is echoed be several other researchers, who have graded patient satisfaction as a critical component in assessing the overall evaluation of healthcare services (Alarcon-Ruiz, Heredia, \& Taype-Rondan, 2019) (Kash \& McKahan, 2017).

As such, when it comes to patient's care, customer satisfaction actually becomes a reasonable and genuine goal as well as a prerequisite to quality of care (Calabro, Raval, \& Rothstein, 2018) as it attempts to align the patient's health requirements and the actual service provided (Velmurugan, Shubasini, Saravana Bhavan, \& Selvam, 2019). In fact, research conducted in recent years on this topic, has gained huge recognition as a matter of quality measurement, especially after the publication of the 1983 NHS Management Inquiry (Hyde, Granter, Hassard, \& McCann, 2016), which called for a collation of user opinions and advocated changes to reach customer and staff satisfaction.

If a patient has positive perceptions, then there is a bigger chance of his/her treatment translating into positive outcomes for the healthcare provider. On the other hand, if the patient has negative perceptions and is dissatisfied with their experience, it may lead to the patient seeking other healthcare providers and, in some extreme cases, some patients may resort to negative word-of-mouth which disappoints and drives away other people and patients seeking healthcare from the provider (Berkowitz, 2016).

Moreover, though the business case for greater consumer satisfaction in the healthcare system is valid in and of itself, another and arguably more important aspect lies in the findings of several studies that prove that there is a significant association between patient satisfaction and patient compliance when it comes to keeping the appointments, having the intentions to be compliant with the recommended treatment plan and the actual use of medication (Joseph \& Ganesan, 2015; Bientzle, Fissler, Cress, \& Kimmerle, 2017).

In order for healthcare service providers to truly ascertain the experience and perceptions of their patients, it becomes necessary to research and recognize the terms and ways in which these patients perceive and evaluate their healthcare service quality. It is also worth noting that patients today are generally more aware, more educated, and have more access to information, resulting in higher expectations of the medical health system (Katre, 2014). It therefore becomes even more essential to set proper measures that can help in achieving the following goals:

- The Monitoring and reporting of improvements

- Detection of areas that require quality improvement initiatives

- Provide a mode of accountability for performance after implementation of any improvements to the system (Institute of Medicine, 2013)

With this in mind, we then need to identify the factors that can actually affect the satisfaction of the patient. These elements are either related to the provider or related to the patient (Shabbir, et al., 2018). Some of the factors that are related to the provider may include proficiency and interpersonal communication skills of the physician, hospital staff behavior, ease of access to care, availability of basic medical center facilities, and infrastructure.

Patient related factors may include socio-demographic features of the patients, type and severity of the disease, and the patients' view and perception of the relationship with the doctor; that is, their sense of trust as well as their involvement in making the decision regarding their care and treatment (Institute of Medicine, 2001; Harper \& Gamlin, 2003; Michael, Schaffer, Egan, Little, \& Pritchard, 2013).

In conclusion, the purpose of placing abundant emphasis on the satisfaction of the patient is twofold, the business case of increasing the number of patients attending the hospital and therefore increasing revenue and the link to the fact that it will result in improvement of compliance of doctors' instructions, care seeking by the patient on time, and greater understanding and remembering the information provided by the healthcare service provider.

\subsection{Related Studies}

Based on the dimensions identified in the previous chapter, this section will examine each facet individually, starting with marketing effectiveness, followed by personnel quality, hospital infrastructure and concluding with a review of the clinical care process, gleaning insights from studies conducted on each subject matter and presenting accurately and concisely. 


\section{Marketing Effectiveness}

Marketing teams are facing increased demands and burdens to reveal results from their expenditures, especially in this era of continuous financial challenges. Instead of raw revenue calculations, true success appears to be founded in linking the actual patient experience into the marketing equation (Gelb, 2015). Marketing effectiveness and patient satisfaction are the two aspects that can help determine the overall effectiveness of care received (Berkowitz, 2016).

In any hospital set up, the marketing of healthcare services needs to center around those two aspects even more vigorously, owing to the distinguishing and critical features of the healthcare services that differentiate and distinguish it from other services, more precisely, the impact it may have on patient's welfare as opposed to pure financial impact.

However, on many occasions, the reason for the dissatisfaction of the customer is not the workers or the staff but it's about a systemic failure in the procedures and rules, policies and communications of the business. Hospitals, as with any other enterprise, flourish only if they keep patient satisfaction and loyalty high by providing excellent services to their clients at an affordable and reasonable price.

It is therefore reasonable to assume that a targeted, scientific approach to marketing in healthcare providers will be just as effective as when this approach is applied to other businesses.

In fact, over the last several years, it was observed that Patient satisfaction is a core metric that can be used to predict the effectiveness of treatments and service quality provided in medical clinics across the world.

Moreover, in the present day, a hospital's performance in a number of functional areas is not measured individually; as there exists a multitude of systems and approaches that depend on the assumptions made about the system itself (Tyagi \& Singh, 2019) (Kotler \& Keller, 2015).. This gives rise to the need for a standardized unit of comparison and makes satisfaction of patient measures more essential than ever.

\section{Personnel Quality}

The human factor is critical for customer and patient experience in the service industry where sustainable growth can be heavily dependent on employee performance (Mohamed, 2016).

In a recent Swedish study, it was found that competence and its development for individual employees (described in this study as personnel quality) is a process that improves overall firm performance. If the staff are able to develop their capabilities by repeating actions, experimenting with new approaches and identifying new opportunities; they will eventually be able to do tasks more quickly and more efficiently as their organizational knowledge of successful interactions become routine (Wikhamn, 2019). Furthermore, when a patient feels that the hospital care team carries themselves in a professional and confident manner, they are more satisfied, especially when the interactions revolve around the individual needs as whole and are not limited to their ailments as a patient (Kash \& McKahan, 2017).

A hospital's staff approach to customer service generally focuses on behavior, more accurately, greeting the patient, improving and maintaining eye contact, proper communication and performing small courtesies and acts of kindness. These can be further enhanced by more management focused considerations such as understanding the patient's expectations, designing patient focused procedures and performance management systems, improving the criteria used for hiring, educating and training the staff as well as service transparency with the patients themselves (Kennedy, 2017).

These aspects of the staff's performance and others dealing with patient "delight", responsiveness, assurance and patient empathy provide the best opportunities to positively impact patient satisfaction as they will increase the likelihood that a patient will recommend the healthcare provider and creating value to the organization (Kennedy, 2017)

\section{The Clinical Care Process}

The clinical care centers on the doctor-patient relationship and is a key aspect of patient satisfaction. It starts with establishing effective communication between the care provider and the patient. This is central to establishing a doctor-patient therapeutic partnership. Some researchers have identified the deterioration of contact between care providers and patients to be one of the major issues plaguing the medical field today stating that the most influential variable of satisfaction with public health services is the conduct of doctors and affiliated staff towards patients (Khouri \& De Boysson, 2018).

Patients generally view doctor visits as a "time-investment" meaning that in the patient's consciousness the more time spent with the doctor, the higher the perceived level service and overall satisfaction (Kash \& McKahan, 2017). Moreover, although it was found that longer waiting times in healthcare centers resulted in lower perceived satisfaction by patients, spending more time with a care provider greatly reduces the perceived dissatisfaction (Xie \& Or, 2017). Other studies, however, have found that this may not always be the case. According to one south American study, the aforementioned associations only hold true for waiting times of less than 90 minutes and with doctor consultation times of more than 15 minutes, meaning that if a patient spent more (Alarcon-Ruiz, Heredia, \& Taype-Rondan, 2019).

Patients also generally feel higher levels of satisfaction when they receive clear and detailed communication 
this is easily understood from their doctors (Kash \& McKahan, 2017). Doctors often make the mistake of assuming that patient satisfaction is directly related to the quality of care and its results rather than the process of its delivery, but it has been proven that the process itself is just as important in establishing patient satisfaction as the technical outcomes of the treatment (Zarei, Daneshkohan, Pouragha, Marzban, \& Arab, 2015). This is to be expected as patients are generally unable to judge or evaluate the technical ability of a physician directly, but can only judge the mannerism, and level of detail of the information provided by the attending medical staff (Velmurugan, Shubasini, Saravana Bhavan, \& Selvam, 2019). At this point, care should be given to the line that needs to be drawn between patient satisfaction and acceptable medical practice. Patient satisfaction measures are typically driven by the fulfillment of the patient's desires where patients with unmet desires have lower levels of perceived satisfaction (Joseph \& Ganesan, 2015). Organizational pressure to achieve high levels of patient satisfaction may then drive doctors to prescribe medication that the patient requests regardless to the side-effects or risks involved (Kash \& McKahan, 2017).

\section{Hospital Infrastructure}

The physical comfort perceived by patients in a hospital setting has an understandable impact on patient satisfaction. It is always recommended that medical care centers maintain an adequate infrastructure for their patients (Velmurugan, Shubasini, Saravana Bhavan, \& Selvam, 2019).

From the review of the available studies, most patients seem to be satisfied with the infrastructure of their chosen healthcare provider however, whether that factor is statistically significant is under some debate and some researchers have concluded that this factor was not directly associated with perceived patient satisfaction (Goben, Abegaz, \& Abdi, 2020). Although, they did go on to state that this may be the result of the use of different analytical tools, study designs, collection methods or the demographic differences between the studies.

Implication for Managers

\section{Methodology of the Study}

\subsection{Research Design}

In this research paper, a correlational quantitative research design that attempts to use statistical date to determine the extent of the relationship between the identified variables was adopted. The researcher has attempted to seek and interpret relationships as well as recognize data trends and patterns between the studied variable while the variables themselves were not manipulated and were identified and studied as they occurred in their natural setting.

\subsection{Study Setting}

The research was conducted in the kingdom of Bahrain in the period between 2019 and 2020. An online survey was distributed on the patients from the randomly chosen private medical centers in the country.

\subsection{Population and Sampling Method}

This research paper utilized the two-stage clustered sampling method that employs the use of clusters of individuals as the sampling unit. In this study, the population (Residents of kingdom of Bahrain utilizing the services of private medical centers) were divided into different sub-groups, each represented by a different private hospital. This was followed by a random selection of the individuals who participated in the actual study. Careful consideration was given to choosing the clusters to ensure that they were representative of the population.

The sample consisted of a number of patients from the following three private hospitals: (Al-Hilal hospital, Ibn-Alnafees hospital and Noor specialist hospital) in the kingdom of Bahrain

\subsection{Sample size}

In order to make sure that the result to be obtained from this research was truly and rightly representative of the population and can be generalized, it was essential to determine the exact sample size needed for this study. The minimum sample size was a total of 270 subjects. This was calculated using Cochran's Formula for sample size considering the population of residents of the Kingdom of Bahrain utilizing the services of private medical centers. The researcher has opted to use Cochran's formula rather than slovin's as the proportion of the population attending private medical centers in the kingdom of Bahrain is known to be $22.3 \%$ based on the statistics issued by (Ministry of Health, 2017). This coupled with the relatively large population results in an unnecessarily large sample size when using slovin's formula (Tejada \& Punzalan, 2012).

\subsection{Research Instrument}

The sample frame includes private hospital patients. That is why, an online based survey-questionnaire has been identified as the most appropriate method in this study. The questionnaire included three parts. Part A included a profile of the patients of the private hospitals. While Part B included questions on patient satisfaction, Part $\mathrm{C}$ included Clinical Care Process, hospital infrastructure, personnel quality and marketing effectiveness.

Questions listed in part B used a five-point Likert scale to measure patient satisfaction. In Part C, Questions 
related to the clinical care process, Personnel Quality and Marketing effectiveness also used the same five-point Likert scale while questions related Hospital Infrastructure were dichotomous and required only a "Yes or No" response. Validation of the questionnaires were taken from a group of experts

\subsubsection{General Questionnaire}

- Gender

- Age of Respondent

- Education

- Private Hospital In Question

3.5.2. Patient's questionnaire

Table 3.1 Patient Satisfaction ${ }^{\text {a }}$

Item No. Patient satisfaction

1. How satisfied are you with the services provided by the hospital

2. How likely are you to visit the hospital again

3. How satisfied are you with the overall appointment making process in the hospital

4. How easy was it to book your appointment on the date you wanted

5. How likely are you to recommend this hospital to your family / friends

${ }^{a}$ Questions are answered utilizing a five-point Likert scale

Table 3.2 Patient Views Towards Various Aspects of Clinical Care Process ${ }^{a}$

Item No. Clinical care process

1. Doctor Provided an opportunity to talk about my illness

2. Doctor provided enough information regarding my health/condition

3. Doctor provided understandable instructions regarding dose and time of medication

4. Doctor satisfactorily explained side effects of medication

5. Doctor satisfactorily explained the reason of advising further tests

${ }^{a}$ Questions are answered utilizing a five-point Likert Scale

Table 3.3 Patient Views on Various Aspects of Hospital Infrastructure ${ }^{a}$

\begin{tabular}{cl}
\hline Item No. & \\
\hline 1. & Reception disk was easy to locate \\
2. & Waiting area was comfortable \\
3. & Availability of adequate seating \\
4. & Availability of drinking water \\
5. & Cleanliness of hospital facilities \\
6. & Staff in waiting area treated patients on fair ground \\
\hline auestions are answered utilizing a dichotomous "Yes / No" Scale
\end{tabular}

Table 3.4 Patient Views on Various Aspects of Personnel Quality ${ }^{\mathrm{a}}$

\begin{tabular}{cl}
\hline Item No. & \\
\hline 1. & How respectful was your doctor \\
2. & How friendly was the receptionist when you arrived at the hospital \\
3. & How respectful was the staff in the waiting area \\
4. & How clear were the pharmacist's instructions for taking the medication \\
5. & Staff clearly communicated the details of any test/sample before performing the procedure \\
\hline${ }^{a}$ Questions are answered utilizing a five-point Likert scale
\end{tabular}

Table 3.5 Marketing Effectiveness ${ }^{\text {a }}$

\begin{tabular}{cl}
\hline Item No. & Marketing effectiveness \\
\hline 1. & How familiar are you with the hospital and the services it provides \\
2. & How satisfied are you with the prices of the services provided by the hospital \\
3. & How would you describe your overall opinion of the hospital \\
5. & The hospital has a very good reputation in the kingdom of Bahrain \\
\hline auestions are answered utilizing a five-point Likert Scale
\end{tabular}

\subsection{Validity and Reliability}

The Validity of this research paper was maintained though close follow-up, input and feedback from a qualified group of academics. In determining the questionnaire's validity, it was examined and approved by a group of three 
experts who were called for to provide their comments and suggestions to help improve the questionnaire. By procedures, the members of the group were asked to identify if the items contained in the survey instrument are appropriate in collecting the data for the study.

The obtained validity was satisfactory, and according to the criteria set forth by Carter V. Good and Douglas Scates, the research instrument is valid.

Moreover, to evaluate the reliability factor of the questionnaire Alpha-Cronbach was used with a minimum value of 0.7 which is acceptable in the research field. The reliability coefficient was tested with Pearson's Correlation between the scores. The value for a Pearson's coefficient can fall between 0.00 (no correlation) and 1.00 (perfect correlation). A Pilot study that will be conducted for that specific reason. (Kistin \& Silverstein, 2015) states that pilot studies were used for testing of the questionnaire on a minor number of respondents (sample) to find and remove any potential problem.

Table 3.6 Reliability Statistics

\begin{tabular}{lll}
\hline Variables & Cronbach's Alpha & No. of Items \\
\hline Patient Satisfaction & 0.848 & 5 \\
Clinical Process & 0.805 & 5 \\
Hospital Infrastructure & 0.701 & 5 \\
Personnel Quality & 0.817 & 5 \\
Marketing Effectiveness & 0.823 & 5
\end{tabular}

Table 3.6 outlines the reliability statistics for the survey conducted. There were 25 questions listed in the survey divided over 5 variables and mostly utilizing a Likert scale. The internal consistency of the five sections of the satisfaction questionnaire was satisfactory. Cronbach's alpha for patient satisfaction, clinical process, hospital infrastructure, personnel quality and marketing effectiveness were all above the acceptable limit of 0.7 .

\subsection{Data Gathering Procedure}

To gather the information from the population in this research, a questionnaire-based method was used. It included the buildup of numerical data through organized polling which was utilized to gather essential information from the samples (Hair Jr, Wolfinbarger, Money, Samouel, \& Page, 2015).

(Hair Jr, Wolfinbarger, Money, Samouel, \& Page, 2015) also stated that a structured questionnaire is actually a scientifically designed instrument for the measurement of key characteristics of individuals, companies, events or other phenomena. This type of technique of data gathering would, as a result, permit better control resulting in the researcher being able to figure out what is desired and measuring the variables that are under study (Hair Jr, Wolfinbarger, Money, Samouel, \& Page, 2015).

The delivery of the survey was generally through electronic means. So a distributed copy of the questionnaire was distributed among the patients of the hospital. The patient's permission was, of course, required before handing them the survey.

It should be noted that electronic transmission of the questionnaire resulted in a wider reach improving the end results while maintaining the cost effectiveness of the exercise as compared to personally administered method.

Moreover, E-mailing the survey questionnaire will also allow the participants an opportunity to fill up the questionnaires given at any convenient time or location fitting their busy schedule. Furthermore, respondents may likewise find that answering the questionnaires in a non-confrontational setting will better maintain the anonymity of the respondent while eliminating some of the bias inherent to the procedure (Hair Jr, Wolfinbarger, Money, Samouel, \& Page, 2015)

Data were collected over a period of four weeks. A pilot study was conducted on 15 random subjects at the beginning. Each participant was briefed about the purpose of the study and of course the population was provided with the fact of personal confidentiality of the research before distributing the questionnaire. Filling the questionnaire was considered approval for participation in the study through the online survey. The questionnaire was then collected.

\section{Presentation, Analysis and Interpretation of Data}

\subsection{Presentation of Data}

The below table outlines the demographic data of the respondents. Characteristics of Gender, Age and Education level are tabulated and analyzed. 
Table 4.1 Demographic Data

\begin{tabular}{lcc}
\hline Demographic Characteristic & Frequency & Percentage \\
\hline Gender & & \\
\hline Male & 88 & $31.1 \%$ \\
Female & 195 & $68.9 \%$ \\
\hline Age & 1 & \\
\hline Less than 19 & 86 & $0.3 \%$ \\
$20-29$ & 165 & $50.4 \%$ \\
$30-39$ & 11 & $3.9 \%$ \\
$40-49$ & 20 & $7.1 \%$ \\
More than 50 & & \\
\hline Academic Qualification & 32 & $11.3 \%$ \\
\hline High School & 157 & $55.5 \%$ \\
Bachelors & 90 & $31.8 \%$ \\
Masters & 4 & $1.4 \%$ \\
Doctorate & & \\
\hline
\end{tabular}

As can be gleaned from the above table, most of the respondents were highly educated, where $88.7 \%$ of all respondents held university level degrees. Two thirds of the respondents were female $(68.9 \%)$ and only one third identified themselves as male (31.1\%). $88.7 \%$ of the respondents were between the ages of 20 and 39 . This is to be expected considering the initial observations made in the previous chapters regarding the high cost of private healthcare as respondents would be expected to have considerable income or insurance coverage to justify the shift from the alternative (free governmental healthcare).

\subsection{Analysis of Data}

Table 4.2 Descriptive Statistics

\begin{tabular}{lccc}
\hline & Mean & Std. Deviation & N \\
\hline Patient Satisfaction & 3.9859 & .72919 & 283 \\
Clinical Process & 3.8601 & .65812 & 283 \\
Hospital Infrastructure & 1.8996 & .16790 & 283 \\
Personnel Quality & 4.1187 & .57418 & 283 \\
Marketing Effectiveness & 3.9343 & .61361 & 283 \\
\hline
\end{tabular}

Marketing Effectiveness

Table 4.2 shows that the mean of the Patient Satisfaction variable is 3.985, with a standard deviation of 0.729 , indicating mostly satisfied patients. The responses also don't appear to be very polarized as indicated by the relatively low standard deviation.

For the independent variables, the mean of the Clinical Process variable is 3.860, with a standard deviation of 0.6581 . This indicates that most of the respondents were satisfied with the clinical care process itself, also since we used a five-point Likert scale, the low standard deviation indicates that most responses are within 0.6581 points around the mean.

For the Hospital Infrastructure variable, we found a mean of 1.899, with a standard deviation of 0.1679 . It should be noted that the items for the hospital infrastructure variable were measured on a dichotomous (Yes/No) scale rather than a Likert scale and as such the mean shows a positive outlook towards the variable, again standard deviation is very low and indicates that there are very little variability in the views held by the respondents.

The mean of the Personnel Quality variable is 4.118 , with a standard deviation of 0.6136 . This is also similar to the findings for the clinical care process, still indicating that most respondents are satisfied with perceived personnel quality with very little variability around the mean. Finally, the mean of the Marketing Effectiveness variable is 3.934 , with a standard deviation of 0.6136 .

From the above findings, it can be inferred that most of the patients of private medical centers in the kingdom of Bahrain are satisfied with the factors measured. The low variability indicated by the standard deviation measurements shows very little polarization in the responses. 
Table 4.3 Pearson's Correlation

\begin{tabular}{lccccc}
\hline & $\begin{array}{c}\text { Patient } \\
\text { Satisfaction }\end{array}$ & $\begin{array}{c}\text { Clinical } \\
\text { Process }\end{array}$ & $\begin{array}{c}\text { Hospital } \\
\text { Infrastructure }\end{array}$ & $\begin{array}{c}\text { Personnel } \\
\text { Quality }\end{array}$ & $\begin{array}{c}\text { Marketing } \\
\text { Effectiveness }\end{array}$ \\
\hline Clinical Process & 1.000 & & & & \\
Hospital & 0.615 & 1.000 & & & \\
Infrastructure & 0.445 & 0.327 & 1.000 & & \\
Personnel Quality & 0.597 & 0.679 & 0.384 & 1.000 & \\
Marketing & 0.710 & 0.669 & 0.402 & 0.674 & 1.000 \\
Effectiveness & & &
\end{tabular}

Table 4.3, Pearson Correlations shows that there is a positive correlation between the Clinical Care Process and Patient satisfaction equal to $61.5 \%$. This indicates that there is a fairly strong linear relationship between the clinical care process and patient satisfaction. A similar conclusion can be made between Personnel quality and Patient Satisfaction which also show a positive correlation equal to $59.7 \%$ very close to the one indicated by the clinical care process.

The findings also show that there is a positive correlation between Hospital Infrastructure and Patient satisfaction equal to $44.5 \%$. Although, the linear correlation between hospital infrastructure and patient satisfaction is ranked lowest among the measured variables, it actually matches what was found in other studies on the topic.

Finally, Marketing effectiveness and Patient satisfaction also show a very strong positive correlation equal to $71.0 \%$ indicating a very high relationship between the two variables. Based on this we can conclude that the dependent variable of patient satisfaction is positively correlated with all the independent variables with moderate to strong relationships. All findings were also found to be statistically significant with a P-value less than 0.05 allowing for the rejection of the null hypothesis.

Table 4.4 Model Summary

\begin{tabular}{cccccccccc}
\hline Model & \multirow{R}{*}{} & \multirow{2}{*}{$\begin{array}{c}\mathbf{R} \\
\text { Square }\end{array}$} & $\begin{array}{c}\text { Adjusted } \mathbf{R} \\
\text { Square }\end{array}$ & $\begin{array}{c}\text { Std. Error of the } \\
\text { Estimate }\end{array}$ & $\begin{array}{c}\text { R Square } \\
\text { Change }\end{array}$ & $\begin{array}{c}\text { F } \\
\text { Change }\end{array}$ & df1 & df2 & $\begin{array}{c}\text { Sig. F } \\
\text { Change }\end{array}$ \\
\hline 1 & $0.754^{\mathrm{a}}$ & 0.569 & 0.563 & 0.48212 & 0.569 & 91.770 & 4 & 278 & 0.000 \\
\hline
\end{tabular}

a. Predictors: (constant), marketing effectiveness, hospital infrastructure, clinical process, personnel quality

b. Dependent Variable: Patient Satisfaction

The study further carried out a regression analysis to establish the statistical significance relationship between the independent variables, "Marketing Effectiveness, Hospital Infrastructure, Clinical Process, Personnel Quality and the dependent variable, Patient Satisfaction. Table 4.4 shows value of $R$ equals to 0.754 , this value indicates a good level of prediction of the Patient Satisfaction. Where the value of the $\mathrm{R}$ Square (the coefficient of determination) is equal to 0.569 , which shows that $57 \%$ of the variation in the Patient Satisfaction is explained by the above-mentioned variables, while $43 \%$ is explained by other factors.

Table 4.5 ANOVA Table

\begin{tabular}{cccccc}
\hline Model & Sum of Squares & Df & Mean Square & F & Sig. \\
\hline Regression & 85.325 & 4 & 21.331 & 91.770 & $0.000^{\mathrm{b}}$ \\
Residual & 64.619 & 278 & .232 & & \\
Total & 149.943 & 282 & & & \\
\hline
\end{tabular}

a. Dependent Variable : Patient Satisfaction

b. Predictors: (Constant), Marketing Effectiveness, Hospital Infrastructure, Clinical Process, Personnel Quality

The regression analysis results were presented using regression model summary tables, analysis of variance (ANOVA) table and beta coefficient tables. In Table 4.5, the sum of squares of The Independent factors is equal to 85.325, where the sum of squares of other factors in Patient Satisfaction is 64.619. The difference between the two values (F-ratio) in the one-way ANOVA table is equal to 91.770, which indicates that the independent variables listed above are capable of predicting the patient satisfaction dependent variable. The findings were statistically significant with a p-value less than 0.05 . 
Table 4.6 Coefficients Table

\begin{tabular}{|c|c|c|c|c|c|c|c|}
\hline \multirow[t]{2}{*}{ Model } & \multicolumn{2}{|c|}{$\begin{array}{c}\text { Unstandardized } \\
\text { Coefficients }\end{array}$} & \multirow{2}{*}{$\begin{array}{c}\begin{array}{c}\text { Standardized } \\
\text { Coefficients }\end{array} \\
\text { Beta }\end{array}$} & \multirow{2}{*}{ t } & \multirow{2}{*}{ Sig. } & \multicolumn{2}{|c|}{$\begin{array}{c}\text { 95.0\% Confidence } \\
\text { Interval for B }\end{array}$} \\
\hline & $\boldsymbol{\beta}$ & Std. Error & & & & $\begin{array}{l}\text { Lower } \\
\text { Bound }\end{array}$ & $\begin{array}{l}\text { Upper } \\
\text { Bound }\end{array}$ \\
\hline (Constant) & -0.805 & 0.338 & & $\begin{array}{c}- \\
2.381\end{array}$ & 0.018 & -1.470 & -0.139 \\
\hline Clinical Process & 0.217 & 0.065 & 0.196 & 3.368 & 0.001 & 0.090 & 0.344 \\
\hline $\begin{array}{l}\text { Hospital } \\
\text { Infrastructure }\end{array}$ & 0.707 & 0.189 & 0.163 & 3.733 & 0.000 & 0.334 & 1.080 \\
\hline Personnel Quality & 0.128 & 0.075 & 0.101 & 1.705 & 0.089 & -0.020 & 0.276 \\
\hline Marketing & 0.529 & 0.070 & 0.445 & 7.551 & 0.000 & 0.391 & 0.666 \\
\hline
\end{tabular}

Effectiveness

Table 4.6 shows the $\beta$ values of the regression equation and the level of significance. The equation can be listed as follows:

Patient Satisfaction $=0.217($ Clinical Process $)+0.707$ (Hospital Infrastructure $)+$

0.128(Personnel Quality) + 0.529(Marketing Effeciveness) - 0.805

By reviewing the p-values for the different predictors, we find that all the independent variables have a statistically significant impact on the dependent variable except for personnel quality which has a p-value of 0.089 that is higher than 0.05 . As such, we fail to reject the null hypothesis for the independent variable (Personnel Quality).

\subsection{Interpretation of Data}

By examining the questions posed in the beginning of this research paper, we can now answer the questions of what the effect of the different independent variables on patient satisfaction is. This was achieved by conducting a survey on 283 participants.

The survey method used has shown high reliability and internal consistency based on the findings shown in table 3.6 for finding Cronbach's alpha with most showing an alpha value higher than 0.7.

It has also shown that most respondents were generally satisfied with private hospitals in the kingdom of Bahrain with the mean value for satisfaction being 3.9859 with low variability around the mean as measured by the standard deviation $(0.72919$. The model predictors also seem to be satisfactory and were capable of explaining $57 \%$ of the variation surrounding patient satisfaction. All the independent variables were found to have a positive correlation with the dependent variable with values ranging from $44.5 \%$ to $71.0 \%$ indicating moderate to strong relationships between the variables where higher scores for each variable indicate higher levels of perceived patient satisfaction.

The regression analysis conducted on the model using the ANOVA method has revealed that the model is statistically capable of predicting patient satisfaction with a p-value that is much less than 0.05 with each of the predictors being by itself statistically capable of impacting patient satisfaction with the exception of personnel quality which although does not meet our standard of $\mathrm{p}<0.05$ is still quite high with $\mathrm{p}<0.1$ at 0.089 and as such cannot be entirely ignored.

The regression equation showed that for each level of increase in the clinical process, there is a 0.217 increase in patient satisfaction, while for every level of increase in hospital infrastructure, we would find a 0.707 increase in patient satisfaction. Similarly, for every level of increase in marketing effectiveness, we would note a 0.529 increase in patient satisfaction.

Finally, personnel quality, was found not to significantly impact patient satisfaction with a p-value of 0.089. This result does not match the findings of similar studies conducted by different researchers and may be the result of differences in population characteristics, sociodemographic differences or differences in the collection tools and methods. However, it should be noted that this p-value is still $>0.1$ and cannot be completely ignored.

\section{Summary, Conclusion and Recommendation}

\subsection{Summary of Findings}

We have started this study with four key questions that attempted to measure the current level of satisfaction of patients attending private healthcare medical centers in the Kingdom of Bahrain as well as listing the criteria affecting the satisfaction of those patients while finally address the gaps identified in the level of patient satisfaction. These questions addressed the following variables:
A. Marketing Effectiveness
B. Hospital Infrastructure
C. The Clinical Process
D. Personnel Quality 
All the aforementioned variables have been proven to have a significant impact on patient satisfaction and the null hypothesis is rejected except for personnel quality where we failed to reject the null hypothesis due to a p-value of 0.089 which is greater than the designated limit of 0.05 . As mentioned earlier this may be due to differences in population characteristics, sociodemographic differences or differences in the collection tools and methods. Furthermore, this may also be explained by the fact that most of the respondents were outpatients that have very limited interactions with hospital staff a second sampling may offer further insights to this finding.

Generally speaking, patients seem to be currently satisfied with the care provided by private medical centers in the kingdom of Bahrain. Doctors are capable of professional and agreeable interactions with the patients throughout the clinical process,. However, it was noted that the survey measured only $50.5 \%$ of doctors have actively explained the side-effects of prescribed medication.

Hospital infrastructure seems to be at acceptable levels with high levels of quality staff and high marketing effectiveness considering the means calculated.

\subsection{Conclusion}

Health care leaders once felt that only patient recovery results were the only determining factors for patient satisfaction. While other factors such as the clinical process and marketing effectiveness were meant for other industries and businesses but had very limited usage in the healthcare sector.

Today, however, it is known that patient satisfaction is a complicated amalgamation of different factors and circumstances that can in fact, affect the recovery process of the patient instead of it being the other way around.

Those factors - namely the clinical care process, personnel quality, hospital infrastructure and marketing effectiveness - are viewed as a necessity that provide a hospital with a competitive advantage that can draw both patients and business partners to increase the level of success.

In business, having a proactive, well thought out operations/business model will only lead to the success of the company. We should not make the mistake of believing that the success of a healthcare facility is any different. Only such a facility that can address all the factors and integrate them into its business plan will be able to succeed in this new age of healthcare that strives to control costs while maintaining the quality of care provided and gaining access to the latest technology and improvements needed to achieve their noble goals of providing the best possible health care services to the public because providers that understand how patients view and rate service quality most likely will be better able to improve it.

It is the view of this researcher that armed with the knowledge provided by understanding the factors governing patient satisfaction, healthcare providers can further improve their patients' experience, better deliver on their promises of excellent service and further sustain the organization in the future.

\section{References}

Alarcon-Ruiz, C. A., Heredia, P., \& Taype-Rondan, A. (2019). Association of waiting and consultation time with patient satisfaction: secondary-data analysis of a national survey in Peruvian ambulatory care facilities. $B M C$ health services research, 19(1), 439.

Al-Balushi, S., \& Rahman Khan, F. (2017). Factors influencing the preference of private hospitals to public hospitals in Oman. nternational Journal of Management, Innovation \& Entrepreneurial Research EISSN, 2395-7662.

Almasqati, M., Victor, S., \& Mohammed, A. (2020, april 25). Question identification intreview. (F. Juma, Interviewer)

Berkowitz, B. (2016). The patient experience and patient satisfaction: measurement of a complex dynamic. OJIN, $21(1)$.

Bientzle, M., Fissler, T., Cress, U., \& Kimmerle, J. (2017). The impact of physicians' communication styles on evaluation of physicians and information processing: A randomized study with simulated video consultations on contraception with an intrauterine device. Health Expectations, 20(5), 845-851.

Calabro, K. A., Raval, M. V., \& Rothstein, D. H. (2018). Importance of patient and family satisfaction in perioperative care. Seminars in Pediatric Surgery, 27(2), 114-120.

East, R., Singh, J., Wright, M., \& Vanhuele, M. (2017). Consumer behaviour: Applications in marketing. London: Sage.

Gajovic, G., Kocic, S., Radovanovic, S., Ilic, B., Milosavljevic, M., Radevic, S., \& Ignjatovic, D. R. (2012). Satisfaction of users in primary health care. HealthMED, 4185-4193.

Gelb. (2015). Patient Experience: The Key to Marketing Effectiveness. Texas: Gelb Consulting Group, Inc.

Gill, H. S., \& Kaur, N. (2019). An Investigation of Expectations and Level of Services Received by Urban Patients: A Gap Analysis. Journal of the Gujarat Research Society, 21(3), 359-367.

Goben, K. W., Abegaz, E. S., \& Abdi, S. T. (2020). Patient satisfaction and associated factors among psychiatry outpatients of St Paulo's Hospital, Ethiopia. General Psychiatry, 33(1).

Hair Jr, J. F., Wolfinbarger, M., Money, A. H., Samouel, P., \& Page, M. J. (2015). Essentials of business research 
methods. Routledge.

Hanssens, D. M., \& Pauwels, K. H. (2016). Demonstrating the Value of Marketing. Journal of Marketing, 80(6), 173-190.

Harper, P., \& Gamlin, H. (2003). Reduced outpatient waiting times with improved appointment scheduling: A simulation modelling approach. OR Spectrum, 25, 207-222.

Hyde, P., Granter, E., Hassard, J., \& McCann, L. (2016). Deconstructing the Welfare State: Managing Healthcare in the Age of Reform. Routledge.

Institute of Medicine. (2001). Crossing the Quality Chasm: A New Health System for the 21st Century. US: The National Academies Press.

Institute of Medicine. (2013). Toward quality measures for population health and the leading health indicators. (C. o. Indicators, Ed.) US: National Academies Press.

Joseph, L., \& Ganesan, P. (2015). A Study of the Determinants of Patient Satisfaction Using Discriminant Analysis. Global Management Review, 10(1), 43-57.

Kash, B., \& McKahan, M. (2017). The Evolution of Measuring Patient Satisfaction. Journal of Primary Health Care and General Practice, 2015-2018.

Katre, A. N. (2014). Assessment of the correlation between appointment scheduling and patient satisfaction in a pediatric dental setup. International journal of dentistry, 2014.

Kennedy, D. M. (2017). Creating an Excellent Patient Experience Through Service Education: Content and Methods for Engaging and Motivating Front-Line Staff. Journal of Patient Experience, 4(4), 156-161.

Khouri, R., \& De Boysson, T. (2018). A Healthcare Prescription for the GCC. Investcorp.

Kistin, C., \& Silverstein, M. (2015). Pilot studies: a critical but potentially misused component of interventional research. The Journal of the American Medical Association, 314(15), 1561-1562.

Kotler, P., \& Keller, K. (2015). Marketing Management. Harlow: Pearson Education.

Krot, K., \& Rudawska, I. (2019). Is Patient Satisfaction the Key to Promote Compliance in the Health Care Sector? Economics \& Sociology, 12(3), 291-300.

Lane, D. M., D., S., Hebl, M., Guerra, R., Osherson, D., \& Zimmer, H. (2017). Introduction to Statistics. Independent.

Leedy, P., \& Ormrod, J. (2018). Practical Research: Planning and Design. Pearson.

Michael, M., Schaffer, S. D., Egan, P. L., Little, B. B., \& Pritchard, P. S. (2013). Improving wait times and patient satisfaction in primary care. Journal for Healthcare Quality, 35(2), 50-60.

Ministry of Health. (2015). Health Improvement Strategy 2015 - 2018. Kingdom of Bahrain.

Ministry of Health. (2017). Health Summary Statistics. Kingdom of Bahrain.

Mohamed, L. M. (2016). Assessing the effects of transformational leadership: A study on Egyptian hotel employees. Journal of Hospitality and Tourism Management, 27, 49-59.

Mukhtar, F., Anjum, A., Bajwa, M. A., Shahzad, S., Hamid, S., Masood, Z. M., \& Ramsha, M. (2013). PATIENT SATISFACTION; OPD services in a Tertiary Care Hospital of Lahore . The Professional Medical Journal, 20(6), 973-980.

Oflazoglu, S. e. (2017). Qualitative versus Quantitative Research.

Shabbir, H., Raza, A., Malik, T. M., Abbasi, S. U., Ghani, U. F., \& Qadri, A. (2018). Better Communication Reduces Patients' Complaints in OPDs Where There are Prolonged Waiting Time. Pakistan Journal of Medical and Health Sciences, 13(1), 329-331.

Tejada, J. J., \& Punzalan, J. R. (2012). On the misuse of Slovin's formula. The Philippine Statistician, 61(1), 129136.

Tyagi, A., \& Singh, P. (2019). Hospital performance management: A multi-criteria decision-making approach. International Journal of Healthcare Management, 12(4), 286-291.

Velmurugan, G., Shubasini, R., Saravana Bhavan, N., \& Selvam, V. (2019). A Study on Service Quality of a Health Care Organization. International Journal of Online Engineering, 15(10), 91-106.

Wikhamn, W. (2019). Innovation, sustainable HRM and customer satisfaction. International Journal of Hospitality Management, 76, 102-110.

Xie, Z., \& Or, C. (2017). Associations Between Waiting Times, Service Times, and Patient Satisfaction in an Endocrinology Outpatient Department: A Time Study and Questionnaire Survey. INQUIRY: The Journal of Health Care Organization, Provision, and Financing, 54.

Zarei, E., Daneshkohan, A., Pouragha, B., Marzban, S., \& Arab, M. (2015). An empirical study of the impact of service quality on patient satisfaction in private hospitals, Iran. Global journal of health science, 7(1), 1-9. 